\title{
Three key affordances for serendipity
}

Toward a framework connecting environmental and personal factors in serendipitous encounters

Björneborn, Lennart

Published in:

Journal of Documentation

DOI:

10.1108/JD-07-2016-0097

Publication date:

2017

Document version

Peer reviewed version

Citation for published version (APA):

Björneborn, L. (2017). Three key affordances for serendipity: Toward a framework connecting environmental and personal factors in serendipitous encounters. Journal of Documentation, 73(5), 1053-1081.

https://doi.org/10.1108/JD-07-2016-0097 


\title{
Three key affordances for serendipity:
}

\section{Toward a framework connecting environmental and personal factors in serendipitous encounters}

\author{
Lennart Björneborn \\ Royal School of Library and Information Science, University of Copenhagen, \\ Denmark \\ Preprint of paper published Oct. 2017 in Journal of Documentation, 73(5): 1053-1081 \\ https://doi.org/10.1108/JD-07-2016-0097
}

\begin{abstract}
Purpose - Serendipity is an interesting phenomenon to study in information science as it plays a fundamental - but perhaps underestimated - role in how we discover, explore, and learn in all fields of life. The purpose of this paper is to operationalize the concept of serendipity by providing terminological 'building blocks' for understanding connections between environmental and personal factors in serendipitous encounters. Understanding these connections is essential when designing affordances in physical and digital environments that can facilitate serendipity.

Approach - In this paper, serendipity is defined as what happens when we, in unplanned ways, encounter resources (information, things, people, etc.) that we find interesting. In the outlined framework, serendipity is understood as an affordance, i.e. a usage potential when environmental and personal factors correspond with each other. The framework introduces three key affordances for facilitating serendipity: diversifiability, traversability, and sensoriability, covering capacities of physical and digital environments to be diversified, traversed, and sensed. The framework is structured around couplings between the three key affordances and three key personal serendipity factors: curiosity, mobility, and sensitivity. Ten sub-affordances for serendipity and ten coupled personal sub-factors are briefly outlined. Related research is compared with and mapped into the framework aiming at a theoretical validation. The affordance approach to serendipity is discussed, including different degrees and types of serendipity.

Findings - All the terminological 'building blocks' in the framework are seen to resonate with the included related research. Serendipity is found to be a commonplace phenomenon in everyday life. It is argued that we cannot "engineer" nor "design" serendipity per se, but can design affordances for
\end{abstract}


serendipity. Serendipity may thus be intended by designers, but must always be unplanned by users. The outlined affordance approach to serendipity points to the importance of our sensory-motor abilities to discover and explore serendipitous affordances.

Research implications/limitations - Implications of the framework for designing physical and digital environments with affordances for serendipity are briefly considered. It is suggested that physical environments may have a primacy regarding affordances of sensoriability for facilitating serendipity, and digital environments a primacy regarding traversability, whereas physical and digital environments may afford similar degrees of diversifiability. In future research, the framework needs further empirical validation in physical and digital environments.

Originality/value - No other research has been found addressing affordances for serendipity and connections between environmental and personal factors in similarly detailed ways. The outlined framework and typology may function as a baseline for further serendipity studies.

Keywords - Design, Affordances, Serendipity, Information encountering, Information behaviour, Individual behaviour

Paper type - Conceptual paper

\section{Introduction}

Imagine that you enter an environment providing a rich diversity of resources. It could be any blend of resources - physical, digital, and human (i.e. people) - giving insights into the manifold ways in which we obtain experiences and knowledge. Imagine also that this environment allows you to traverse its terrain in different ways and make use of your senses for discovering and exploring its resources. An environment designed like this - e.g., an urban area, a library, a museum, and other settings that stimulate encounters with people, things, information, etc. - would provide affordances for serendipity, following the conceptual framework outlined in this paper.

Serendipity happens when we, in unplanned ways, encounter resources (information, things, people, etc.) that we find interesting. Recent years have seen a proliferating volume of research (e.g., reviews in McCay-Peet, 2013; Foster and Ellis, 2014; Agarwal, 2015) suggesting that serendipity plays an integral role in how we discover, explore, and learn in all fields of life. Serendipity is thus a fundamental - but perhaps underestimated - phenomenon in our life and culture.

Examples include serendipity as micro-learning experiences (D'Ignazio, 2014) as well as groundbreaking discoveries (e.g., Roberts, 1989). Serendipitous encounters can influence life paths and careers (Bandura, 1982) as well as appear in everyday life incidents (e.g., Bogers and Björneborn, 2013), play and creativity (e.g., André et al., 2009; Anderson, 2013), reading for pleasure (Ross, 1999), spontaneous learning (Gopnik, 2011), jazz improvisation (McBirnie, 2008), urban exploration (Hornecker et al., 2011), online news (Yadamsuren and Erdelez, 2010), microblogging (Buchem, 
2011), tagging museum databases (Chan, 2007), innovation (Johnson, 2010), entrepreneurship (Dew, 2009), coworking spaces for freelancers (Olma, 2012), strategic communication (Knudsen and Lemmergaard, 2014), basic research (Handelsman, 2015), interdisciplinary research (Darbellay et al., 2014), and many other fields and references beyond the limits of this paper.

Growing awareness of this influence of serendipity on expanding our 'information horizons' (cf. Sonnenwald et al., 2001), thus counteracting limiting 'filter bubbles' (Pariser, 2011), has in recent years created increased attention on how physical and digital environments can be designed to facilitate serendipity. Examples here include (mentioning only few selected references) workplace design (Jeffrey and McGrath, 2000), urban design (Zuckerman, 2011), library design (Björneborn, 2008), search engines (Rahman and Wilson, 2015), music recommendation (Taramigkou et al., 2013), and much more.

The present conceptual paper outlines a framework understanding serendipity as an affordance (Gibson, 1977), i.e. as an "actionable propert[y] between the world and an actor (a person or animal)" (Norman, 1999: 39). In other words, serendipity can be seen as a usage potential (Björneborn, 2008) through a correspondence between environmental and personal factors. The conceptual framework aims to provide a terminology and typology to understand what environmental and personal factors correspond with each other in serendipitous encounters. In this context, the framework also aims to provide potential terminological 'building blocks' for design of physical and digital environments that can facilitate serendipity. No other research has been found addressing affordances for serendipity and connections between environmental and personal factors in similarly detailed ways.

In the paper, related research is compared with and mapped into the outlined framework aiming at a theoretical validation. The affordance approach to serendipity is further elaborated. The deliberately 'low-scale' terms unplanned, encounter, and interesting in the above definition of serendipity are discussed in more detail. In this context, different degrees and types of serendipity are addressed, including serendipity as a commonplace phenomenon in everyday life. Implications of the framework for designing physical and digital environments with affordances for serendipity are briefly considered.

\section{Related research}

Comparing the presented framework with related research, eleven approaches for understanding serendipity and akin phenomena are included and mapped into the framework, cf. Table 1. Included research was selected from both often-cited and newer literature, with theoretical as well as empirical approaches, which could supplement each other regarding details on environmental as well as personal serendipity factors. The related research is only briefly summarized here before addressed in subsequent sections outlining the framework. 


\begin{tabular}{|c|c|c|c|c|c|c|c|c|c|c|c|}
\hline \begin{tabular}{|l|} 
Walpole \\
1754 \\
\end{tabular} & \begin{tabular}{|l|} 
Merton \\
1948 \\
\end{tabular} & \begin{tabular}{|l|} 
Austin \\
1978 \\
\end{tabular} & \begin{tabular}{|l|} 
Bawden \\
1986 \\
\end{tabular} & \begin{tabular}{|l|} 
van Andel \\
1994 \\
\end{tabular} & $\begin{array}{l}\text { Fine \& D. } \\
1996\end{array}$ & $\begin{array}{l}\text { Rubin et al. } \\
2011\end{array}$ & $\begin{array}{l}\text { Makri \& BI. } \\
2012\end{array}$ & $\begin{array}{l}\text { Bogers \& Bj. } \\
2013\end{array}$ & $\begin{array}{l}\text { Makri et al. } \\
2014\end{array}$ & $\begin{array}{l}\text { McCay-Peet \& Toms } \\
2015\end{array}$ & \begin{tabular}{|l}
$\begin{array}{l}\text { Present } \\
\text { framework }\end{array}$ \\
\end{tabular} \\
\hline \multirow[t]{19}{*}{ accident } & & Chance I & $\begin{array}{l}\text { info-rich environ. } \\
+ \text { informal chann. }\end{array}$ & & chance & chance & & & & trigger-rich & \multirow{3}{*}{ 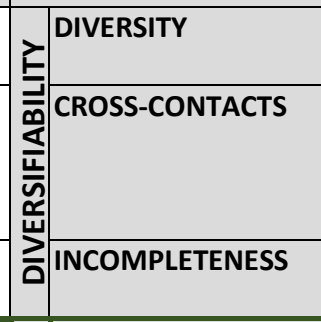 } \\
\hline & & Chance I & $\begin{array}{l}\text { interdisciplinary } \\
\text { info. }\end{array}$ & $\begin{array}{l}\text { 5. side-effect } \\
\text { 6. by-product } \\
\text { 9. inversion } \\
\text { 11. outsider etc. } \\
\end{array}$ & & & & & & enables connections & \\
\hline & & Chance I & $\begin{array}{l}\text { peripheral \& } \\
\text { speculative info. }\end{array}$ & $\begin{array}{l}\text { 4. successful error } \\
\text { 7. wrong hypothesis }\end{array}$ & & & & & & & \\
\hline & & Chance II & & & & & & & & enables connections & \multirow{4}{*}{ 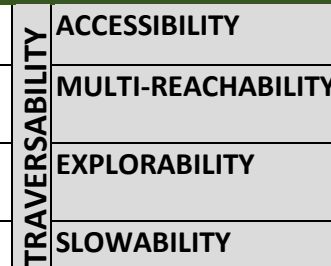 } \\
\hline & & Chance II & & & & & & & & enables connections & \\
\hline & & Chance II & $\begin{array}{l}\text { facilitating } \\
\text { browsing }\end{array}$ & & & & & & & enables connections & \\
\hline & & Chance II & & & & & & & & enables connections & \\
\hline & & Chance III & & $\begin{array}{l}\text { 3. repetition of } \\
\text { surprising observ. }\end{array}$ & & & & & & $\begin{array}{l}\text { trigger-rich } \\
+ \text { highlights triggers }\end{array}$ & \multirow{3}{*}{ 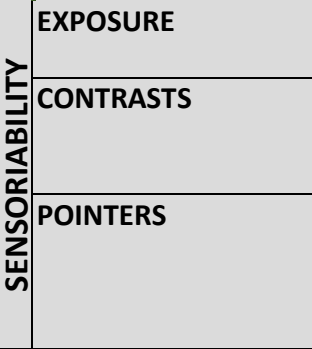 } \\
\hline & $\begin{array}{l}\text { anoma- } \\
\text { lous }\end{array}$ & Chance III & shows exceptions & $\begin{array}{l}\text { 12. disturbance } \\
\text { 13. scarcity } \\
\text { 14. interruption } \\
\end{array}$ & & & & & & $\begin{array}{l}\text { trigger-rich } \\
+ \text { highlights triggers }\end{array}$ & \\
\hline & & Chance III & $\begin{array}{l}\text { shows analogies, } \\
\text { patterns, etc. } \\
\text { + tailoring user } \\
\text { requirements }\end{array}$ & 1. analogy & & & & & & $\begin{array}{l}\text { trigger-rich } \\
+ \text { highlights triggers } \\
+ \text { enables connections } \\
+ \text { enables capturing }\end{array}$ & \\
\hline & strategic & Chance IV & \begin{tabular}{|l|} 
direct user \\
involvement
\end{tabular} & 10. testing & insight & $\begin{array}{l}\text { fortuitous } \\
\text { outcome }\end{array}$ & $\begin{array}{l}\text { value } \\
+ \text { insight }\end{array}$ & value & $\begin{array}{l}\text { looking for patterns } \\
+ \text { seizing opportunity }\end{array}$ & openness & \multirow{3}{*}{\begin{tabular}{|l|} 
interest \\
playfulness \\
inclusiveness
\end{tabular}} \\
\hline & & Chance IV & & $\begin{array}{l}\text { 15. playing } \\
\text { 16. joke }\end{array}$ & & & & & varying routines & openness & \\
\hline & & Chance IV & & $\begin{array}{l}\text { 8. no hypothesis } \\
\text { 17. forgetting } \\
\end{array}$ & & & & & $\begin{array}{l}\text { making mental space } \\
+ \text { relaxing boundaries }\end{array}$ & openness & \\
\hline & & Chance II & & & & & & & & & \multirow{4}{*}{\begin{tabular}{|l|l} 
& searching \\
: & immersion \\
。 & exploring \\
Ė & stumbling \\
\end{tabular}} \\
\hline & & Chance II & & & & & & & & & \\
\hline & & Chance II & & & & & & & & & \\
\hline & & Chance II & & & & & & & & & \\
\hline & & Chance III & & & & $\begin{array}{l}\text { act of } \\
\text { noticing }\end{array}$ & & & being observant & & \multirow{3}{*}{ 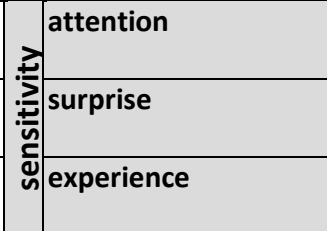 } \\
\hline & $\begin{array}{l}\text { unanti- } \\
\text { cipated }\end{array}$ & Chance III & & 2. surprising observ. & & & unexpected & unexpected & & & \\
\hline sagacity & & Chance III & & & & $\begin{array}{l}\text { prepared } \\
\text { mind }\end{array}$ & & preoccupied & previous experiences & $\begin{array}{l}\text { prepared mind } \\
+ \text { making connections }\end{array}$ & \\
\hline
\end{tabular}

Table 1. Related research mapped into the present framework, cf. Table 2. 
First approach included, cf. Table 1, is Horace Walpole's original definition of "serendipity [...] by accidents and sagacity" when he coined the term in 1754 (Merton and Barber, 2004: 2). It is quoted in fuller length in the discussion further below.

The next approach is Merton's (1948: 506) influential definition of the "serendipity pattern [as] the fairly common experience of observing an unanticipated, anomalous and strategic datum".

Another often-cited approach is Austin's (1978: 76) four types of chance; resulting from "an accident” (Chance I), from “general exploratory behavior" (Chance II), from "sagacity” (Chance III), and from "individualized action" (Chance IV).

Also discussing serendipity, Bawden (1986: 214) suggests nine "aspects that may aid creativity" in information systems: "Overall information-rich environment; Inclusion of peripheral and speculative material; Provision of interdisciplinary information; Representation of information to bring out analogies, patterns, exceptions, etc.; Emphasis on browsing facilities; Direct involvement of information user; Encouragement of information channels [including informal channels]; Information provision geared to individual preferences/requirements; Appropriate use of new information technologies". The last aspect is not included in Table 1 as it is seen as covered by all three key affordances.

Defining serendipity as "the art of making an unsought finding", van Andel (1994) presents a collection of 17 "serendipity patterns" (cf. Merton above): “(1) Analogy; (2) One surprising observation; (3) Repetition of a surprising observation; (4) Successful error; (5) From side-effect to main effect; (6) From by-product to main product ('spin-off'); (7) Wrong hypothesis; (8) No hypothesis; (9) Inversion; (10) Testing of a popular 'belief'; (11) Child, student or outsider; (12) Disturbance; (13) Scarcity; (14) Interruption of work; (15) Playing; (16) Joke; (17) Dream or "forgetting-hypothesis"".

Fine and Deegan (1996) give an often-cited definition of serendipity as "the unique and contingent mix of insight coupled with chance".

Analyzing everyday life occurrences of "chance encounters" mentioned in blogs, Rubin et al. (2011) identify four facets of serendipity: "Facet A: Prepared mind: prior concerns + experiences; Facet B: Act of noticing: observation/attention; Facet C: Chance: accidental nature/perceived lack of control; Facet D: Fortuitous outcome: perceived gain/happy ending”.

Interviewing researchers coming across information serendipitously, Makri and Blandford (2012) identify three common elements: unexpectedness, insight, and value.

Bogers and Björneborn (2013) investigate "micro-serendipity" as "everyday contexts, conditions, and attributes of serendipity" shared on Twitter and discuss three key elements: preoccupation, unexpectedness, and value. 
Interviewing creative professionals, Makri et al. (2014: 2186) identify seven "serendipity strategies": "varying their routines; being observant; making mental space; relaxing their boundaries; drawing on previous experiences; looking for patterns; seizing opportunities".

The last approach included, McCay-Peet and Toms (2015: 1471) list seven factors that may "facilitate the process of serendipity": “(a) four external or environmental factors-trigger-rich, highlights triggers, enables connections, and enables capturing; and (b) three internal factors relating to the individual—openness, prepared mind, and ability to make connections."

The above inclusions from related research are addressed in the following sections outlining the conceptual framework.

\section{Conceptual framework}

The three key affordances for facilitating serendipity cover ten sub-affordances, cf. Table 2 below, based on the ten so-called 'serendipity dimensions' identified by Björneborn (2008) in an empirical study of public libraries. The present conceptual framework was developed through a realization that the ten 'serendipity dimensions' could be grouped into three key affordances, diversifiability, traversability, and sensoriability, dealing with how physical and digital environments can be diversified, traversed, and sensed, thus covering key aspects of human interactions with environments. The three key affordances and ten sub-affordances are explained in more details in the following subsections.

Related research, cf. Section 2 and Table 1, covers both environmental and personal factors in serendipitous encounters. In the present framework, cf. Table 2, environmental factors are covered by the three key affordances and ten sub-affordances. Affordances are here seen as environment-actor correspondences, as will be elaborated further below. In the framework, personal factors are seen as the actoral components of these affordances. The three key affordances for serendipity are thus seen as essentially (but not exclusively) coupled with three key personal factors in the present framework, curiosity, mobility, and sensitivity, as shown in Table 2. Analogously, within the affordance approach, each of the ten sub-affordances is seen as coupled with a personal sub-factor for serendipity in the framework, cf. Table 2. The terminology of the ten personal sub-factors was developed by investigating related research in order to identify essential personal serendipity-related terms that best could correspond with each of the ten sub-affordances in Table 2.

In the distillation process of developing the framework, writing +450 haiku micro-poetry [1] (cf. Appendix B) about serendipity as a phenomenon functioned as an arts-informed research reflection tool (cf. Hartel, 2014) helping to extract essences of the read literature and to crystallize ideas and keywords assembled into the framework terminology in Table 2 and Appendix A. 
In the framework, serendipity is seen as a possible outcome when personal factors of curiosity, mobility, and sensitivity correspond with affordances of diversifiability, traversability, and sensoriability in a given environment. Within the size limits of this paper, personal factors and subfactors are only briefly addressed. Focus is on the three key affordances and their sub-affordances.

\begin{tabular}{|c|c|}
\hline $\begin{array}{c}10 \text { SUB-AFFORDANCES } 3 \text { KEY AFFORDANCES } \\
\text { FOR SERENDIPITY } \\
\text { FOR SERENDIPITY }\end{array}$ & $\begin{array}{c}\begin{array}{c}\text { key personal factors } 10 \text { personal sub-factors } \\
\text { for serendipity for serendipity }\end{array} \\
\end{array}$ \\
\hline $\begin{array}{r}\text { DIVERSITY DIVERSIFIABILITY } \\
\text { [multiple potentials] }\end{array}$ & \begin{tabular}{l|l} 
curiosity & $\begin{array}{l}\text { interest } \\
\text { [regarding diversity etc.] }\end{array}$
\end{tabular} \\
\hline $\begin{array}{l}\text { CROSS-CONTACTS } \\
\text { [colliding potentials] }\end{array}$ & $\begin{array}{l}\text { playfulness } \\
\text { [regarding cross-contacts etc.] }\end{array}$ \\
\hline $\begin{array}{r}\text { INCOMPLETENESS } \\
\text { [unfinalizable potentials] }\end{array}$ & $\begin{array}{l}\text { inclusiveness } \\
\text { [regarding incompleteness etc.] }\end{array}$ \\
\hline $\begin{array}{r}\text { ACCESSIBILITY } \\
\text { [access to specific spot, convergently] }\end{array}$ & 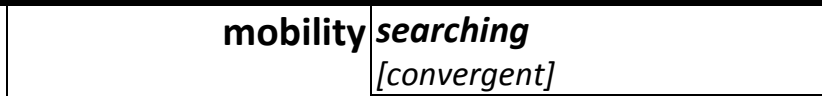 \\
\hline $\begin{array}{r}\text { MULTI-REACHABILITY } \\
\text { [reaching anywhere, immersively] }\end{array}$ & $\begin{array}{l}\text { immersion } \\
\text { [both convergent \& divergent] }\end{array}$ \\
\hline $\begin{array}{r}\text { EXPLORABILITY } \\
\text { [inviting somewhere else, divergently] }\end{array}$ & \begin{tabular}{|l|} 
exploring \\
[divergent]
\end{tabular} \\
\hline $\begin{array}{r}\text { SLOWABILITY } \\
\text { [affording slower pace, frictionally] }\end{array}$ & $\begin{array}{l}\text { stumbling } \\
\text { [both divergent \& convergent] }\end{array}$ \\
\hline $\begin{array}{r}\text { EXPOSURE SENSORIABILITY } \\
\text { [highlighting broader, over longer time] }\end{array}$ & $\begin{aligned} & \text { sensitivity } \text { attention } \\
& \text { [broader sensing] }\end{aligned}$ \\
\hline $\begin{array}{r}\text { CONTRASTS } \\
\text { [highlighting sharper, more suddenly] }\end{array}$ & \begin{tabular}{|l|} 
surprise \\
[unprepared sensing]
\end{tabular} \\
\hline $\begin{array}{r}\text { POINTERS } \\
\text { [highlighting narrower, more specifically] }\end{array}$ & $\begin{array}{l}\text { experience } \\
\text { [prepared sensing] }\end{array}$ \\
\hline
\end{tabular}

Table 2. Key affordances and sub-affordances for serendipity with coupled personal factors and sub-factors.

The one-to-one couplings in Table 2 are made for the sake of focus and overview in order to provide basic insights into the environment-actor correspondences that may provide affordances for serendipitous encounters. Hence, the outlined framework is not meant to be simplistic, as there may be connections between all elements in complex ways. Neither is the framework meant to be deterministic, as affordances in a given environment not automatically lead to specific outcomes including serendipity. Furthermore, all affordances and personal factors in the framework may not need to be present in a given situation or environment in order for serendipity to occur. Neither does the framework claim to be exhaustive nor have mutually exclusive elements, as these may overlap and future research may identify other elements. Nevertheless, the framework aims to provide coherent and fine-grained terminological 'building blocks' for understanding connections between environmental and personal factors in serendipitous encounters. Understanding these connections is essential when designing physical and digital environments that can facilitate serendipity. In this way, the framework aims at an operationalization of the concept of serendipity. 


\subsection{Diversifiability}

According to a dictionary definition, diversifiability is "the quality or capacity of being diversifiable" [2]. In economics, for example, the term is used together with 'diversification' to describe how a wide diversity of investment strategies may reduce financial risks (cf. Frankel, 1979).

In the present framework, diversifiability covers affordances of a physical or digital environment of being diversifiable, that is, how does this environment allow a diversity of contents. Different environments can have different degrees of diversifiability, having contents more or less easily exchangeable and combinable. An example could be a country roadside. The diversifiability of this physical micro-environment partly depends on how biodiversity is invited; how much fauna and flora may thrive given local climate, pollution, etc. The diversifiability also depends on man-made components, for instance, thrown-away litter, unintentionally left-behind belongings, roadwork, etc. This diversifiability may facilitate serendipity, as people, when passing the roadside, without planning for it may encounter and discover potentially interesting flowers, insects, windfalls, animal traces, geological specimens, artwork installations, lost garments and toys, and much more. This example also illustrates that the diversifiability of a given environment - even a small one - and its affordances for serendipity can be quite complex. This example from an environment not normally associated with information provision could perhaps inspire features for diversifiability also in urban areas, libraries, social media, etc., when designing affordances for serendipity. For instance, by allowing for more imperfection, user-generated contents, and juxtapositions of dissimilar objects as elaborated below.

In the framework, diversifiability covers three sub-affordances based on Björneborn (2008): diversity, cross-contacts, and incompleteness [3], cf. Table 2. These sub-affordances deal with different aspects of potentials for encountering diversified contents in a given environment.

\section{Diversity}

The sub-affordance of diversity deals with multiple disparate potentials of a given environment that may facilitate serendipity. The more diverse, heterogeneous, and varied contents and resources in an environment, the more potentials for people to encounter something interesting not planned for or not known in advance. As also noted in the introduction, urban areas and public libraries are examples of physical environments typically containing a rich and dense diversity of contents. Björneborn (2008) discusses " $[\mathrm{h}]$ ow rich is the diversity of topics, genres, resources and activities that users may encounter during a library visit? Not many other places in society contain so many topics in so relatively small an area as public libraries. The topical diversity spans the whole knowledge universe of mankind and may thus trigger the diversity of individuals' interest spaces [...] that may lead to serendipitous findings." The whole Internet and Web are digital environments full of diversity. "The 
information diversity of the Web ensures that there is an endless supply of surprising information to stumble across" (Johnson, 2010: 120). According to McCay-Peet and Toms (2011), serendipitous information retrieval can be seen as "the perhaps inevitable consequence of immersion in an information-rich environment". This is in line with McCay-Peet and Toms (2015) talking about "trigger-rich" environments and Bawden (1986) addressing "information-rich environments" and “informal channels", cf. Table 1.

There is a considerable literature on measures of diversity in different research fields (e.g. review in Stirling, 2007). For example, measuring ecological diversity (e.g. Magurran, 1988) or improving music recommendation through topic diversification (e.g. Ziegler et al., 2005). Björneborn (2004) discussed measures of dissimilarity between topics on web sites.

Diversity in a given environment may occur by coincidence and chance, cf. the roadside example with left-behinds, windfalls, etc. As stated by Bardone (2016), "a chance event is nothing mysterious, as it can be defined as any event that falls outside of one's control". Fine and Deegan (1996) and Rubin et al. (2011) include chance as a factor influencing serendipity, cf. Table 1. In Austin's (1978) four types of chance, 'Chance I' resulting from "an accident" resonates with the coincidental aspects of all three sub-affordances under diversifiability including diversity, cf. Table 1.

\section{Cross-contacts}

The second sub-affordance under the key affordance of diversifiability deals with so-called crosscontacts. Serendipity may happen when dissimilar resources (information, things, people, etc.) meet or collide across contact surfaces, edges, intersections, etc. Like "juxtapositions of disassociated objects and information" [4] it could be dissimilar topics and genres next to each other in library spaces (Björneborn, 2008) that may “enable connections” (McCay-Peet and Toms, 2015; cf. Table 1) across different resources. Cross-contacts also cover how serendipity may occur on boundary crossings between different scientific fields (cf. Darbellay et al., 2014). This echoes Bawden (1986) listing “provision of interdisciplinary information”, cf. Table 1.

Cross-contacts that may facilitate serendipitous encounters happen all the time because the world is full of possibilities combinable in innumerable ways (cf. Hand, 2015). Sheer combinatorics thus constantly shapes cross-contact opportunities for serendipity. The higher the degree of diversifiability in an environment, the easier the contents of this environment can be reconfigured, i.e. remixed, recombined, repurposed, etc., by different actors; possibly providing more affordances for serendipity. Urban areas and social media are examples of such typically easily reconfigurable environments. Van Andel's (1994) “serendipity patterns" of "side-effect”, "by-product”, "inversion”, and "outsider", cf. Table 1, are all instances of how diverse elements can cross borders and reconfigure settings of an environment. 


\section{Incompleteness}

Incompleteness is the third sub-affordance under the diversifiability hat. Serendipity may happen in environments with incomplete, inconsistent, and 'unfinalizable' features that leave potentials open to us. McCarthy and Wright (2005), using a term from Mikhail Bakhtin, describe an "unfinalizable" world "full of potentiality, freedom, newness, and surprise" (p.83). In such open worlds, like many urban areas and social media, serendipity may help us encounter and discover things we do not know we do not know: the unknown unknowns or yet-to-be-knowns.

The incompleteness of an environment includes imperfect 'cracks' (Björneborn, 2008) and affordances for users to leave traces including left-behinds (Björneborn, 2011) of their activities that may lead to unplanned encounters, cf. the roadside example. Serendipity may thus thrive in environments with more imprecision and ambiguity, for example, in libraries using broader categories and classifications with less specificity (cf. Bawden, 1986: 212), perhaps also allowing "peripheral and speculative material" (ibid.: 214), cf. Table 1. Incompleteness also covers van Andel's (1994) "successful error" and "wrong hypothesis", cf. Table 1, related to how "mess tends to loosely weave together disparate elements" (Abrahamson and Freedman, 2007: 98). The 'unfinalizable' incompleteness of the world means serendipity may happen when "niches of opportunity" (Resmini, 2013) constantly but unpredictably emerge. In fact, one may say it is foreseeable that a phenomenon like serendipity exists in an unforeseeable world.

\section{Curiosity as coupled with diversifiability}

In the framework, cf. Table 2, curiosity is a key personal serendipity factor seen as coupled with the key affordance of diversifiability. It is suggested, that the richer affordances for diversity, crosscontacts, and incompleteness of contents in an environment, the more our curiosity may be triggered. Research (e.g., Åkerström, 2013) points to the connection between curiosity and serendipity. This is in line with Case and Given (2016: 7) stating “[o]ur daily life is peppered with instances in which we become interested in learning more about a topic after accidentally encountering some bit of information about it. This sort of curiosity, unmotivated by an immediate goal, is a common aspect of human life and of information behavior." What Austin (1978) calls 'Chance IV' resulting from "individualized actions" (p.76) that include "distinctive [...] hobbies and personal life styles" (p.75) may be seen as favoring the curious open mind, covering all curiosity sub-factors in Table 1.

In the framework, the personal serendipity factor of curiosity is suggested to cover three personal sub-factors: interest, playfulness, and inclusiveness. These are seen as coupled with the three subaffordances of diversifiability outlined above, and they all deal with different emotional approaches (cf. Silvia, 2008) when we interact with an environment. As earlier stated, focus here is on the one- 
to-one couplings in Table 2, for the sake of focus and overview, and the personal sub-factors will only be briefly addressed given the size limits of this paper.

Interest, the first personal sub-factor of curiosity, is in Table 2 coupled with the sub-affordance of diversity. In environments filled with a rich diversity of resources, it may be difficult not to find something interesting that may trigger some of our uncountable, bigger or smaller interests, e.g., on social media, in urban areas, or in libraries (cf. Björneborn, 2008). Serendipitous encounters may thus trigger both emerging situational interests and longer-lasting individual interests (terminology by Hidi and Renninger, 2006). Since childhood, we spontaneously learn from unplanned everyday encounters triggering our interests and curiosity. "Adults often assume that most learning is the result of teaching and that exploratory, spontaneous learning is unusual. But actually, spontaneous learning is more fundamental." (Gopnik, 2011). All three curiosity sub-factors deal with what McCay-Peet and Toms (2015) call "openness", cf. Table 1, "[t]o be curious or open or receptive to experience" (p.1471). The sub-factor of interest is seen as covering the "serendipity strategies" "looking for patterns" and "seizing opportunities" by Makri et al. (2014), and Bawden's (1986) "direct user involvement", cf. Table 1. Van Andel's (1994) "serendipity pattern" of "testing" can be seen as curiosity-/interest-driven. "Perceived gain" (Rubin et al., 2011), "insight” (Fine and Deegan, 1996; Makri and Blandford, 2012), "value" (Makri and Blandford, 2012; Bogers and Björneborn, 2013), and "strategic" (Merton, 1948) all cover how we may consider unplanned encounters as valuable and relevant to our interests, cf. Table 1.

Playfulness, the second personal sub-factor of curiosity, is seen as essentially coupled with the sub-affordance of cross-contacts. Inspired by Walz (2010) discussing "ludic architecture" and "ludic practices in space" (p.133), serendipity can be viewed as a ludic practice in space; as a playful way of tinkering and making use of cross-contacts, etc., encountered in unplanned ways. Creativity is closely related to this playful and imaginative attitude (cf. Austin, 1978). In the present framework, the ability of unplannedness, i.e. not planning all our activities, is seen as a spontaneous, improvising, and playful attitude (cf. Anderson, 2013). This resonates with related research, cf. Table 1; "playing" and "joke" (van Andel, 1994), and "varying routines" (Makri et al., 2014).

Inclusiveness, the third personal sub-factor of curiosity, is here coupled with the sub-affordance of incompleteness. Being flexible and allowing imperfection, uncertainty, and mistakes, may thus be important personal abilities facilitating serendipity, e.g., when we tentatively explore new areas of interest. In related research, cf. Table 1, this echoes "openness" (McCay-Peet and Toms, 2015), "relaxing boundaries" and "making mental space" (Makri et al., 2014), as well as "no hypothesis" and "forgetting" (van Andel, 1994) as inclusive behaviour allowing incompleteness and imperfection. 


\subsection{Traversability}

The term 'traversability' is well known, e.g., in architecture and online gaming. Walz (2010) states that in order for a "building environment to become more involved in the play activity it hosts, the building should feature traversability, thereby allowing for player mobility" (p.269). In a similar vein, Gibson et al. (1987) investigate "the traversability of surfaces by crawling and walking infants" (p.533). In the framework, traversability deals with the quality or capacity of a physical or digital environment of being traversable. How rich affordances are there thus to move through a given environment and reach different resources? In the roadside example, it could be trodden paths giving easier access. In libraries, it could be aisles leading to shelves, or hyperlinks pointing to other webpages.

Traversability as a key affordance for serendipity covers four sub-affordances based on Björneborn (2008); accessibility, multi-reachability, explorability, and slowability (cf. Table 2). These sub-affordances deal with different aspects of how we can make use of the topology, i.e. the spatial layout and interconnectedness, of a given environment.

\section{Accessibility}

The sub-affordance of accessibility deals with how well the topology of a physical or digital environment provides direct access to specific spots and resources. Serendipity may thus happen when we come within reach of potentially interesting resources. In other words, serendipity may be facilitated when topical disparity is combined with topological proximity. Like in a physical library when there is " $[\mathrm{u}]$ nhampered direct access to human, physical, digital information resources" (Björneborn, 2008) or like "floor-level accessibility" in museums (Wineman and Peponis, 2010).

\section{Multi-reachability}

The sub-affordance of multi-reachability deals with to what degree the topology of a given environment let us reach from one spot to another one within this space along many different routes. "Multi-reachability affects freedom of movement and possibilities for serendipity. The more different access routes that users can choose to move along in the library space, the more different resources and topics the users may meet - and the more affordances are present in this space to trigger users' interest spaces" (Björneborn, 2008). In a similar vein, Benjamin et al. (2014: 341) discuss "multiple exploration channels" in a clipart database as supportive for serendipity. Multi-reachability is also related to shortcuts across entangled and 'crumpled-up' 'small-world' structures on the Web with affordances for serendipity due to short network distances between dissimilar topics (Björneborn, 2004). 


\section{Explorability}

The sub-affordance of explorability deals with how well the topology of a given environment invites us to explore this environment. Serendipity may thus happen when physical and digital environments invite us to "move, look around, explore, and browse" (Björneborn, 2008), e.g., in libraries with an organic non-grid layout. Similarly, Bates (2007) talks about "browsable interfaces [consisting] of rich scenes, full of potential objects of interest”. Also Bawden (1986) points to the importance of “facilitating browsing” cf. Table 1. This echoes what Doyle (1963) called 'exploratory capability' to supplement the traditional criterion of 'relevance' for evaluating performance of information retrieval systems (Björneborn, 2004). The concept of explorability is also used by Dörk et al. (2011) as a guiding principle for design of urban or digital environments stimulating "information flaneurs". A similar approach is found in the artistic urban movement of 'psychogeography' offering "playful, inventive strategies for exploring cities [...] just about anything that takes pedestrians off their predictable paths and jolts them into a new awareness of the urban landscape" (Hart, 2004).

\section{Slowability}

The sub-affordance of slowability deals with to what degree the topology of a given environment invites us to slow down, stop, look closer, and examine potentially interesting encountered resources, e.g., by providing seating opportunities in library sections or urban areas. Björneborn (2008) called this sub-affordance stopability seeing it as complementary to explorability. The notion of slowability is inspired by the so-called slow movement including slow design (Poirier and Robinson, 2014). Serendipity may happen in environments supporting slower pace, pauses, and a reflective approach (cf. Anderson, 2013). Paydarfar and Schwartz (2001) thus state "[s]low down to explore. Discovery is facilitated by an unhurried attitude." Slowability and serendipity may also be stimulated in environments providing 'friction' and irregularities including constraints and obstacles, helping us stumble upon potentially interesting resources, like roadwork making us slow down and notice details of an adjacent roadside. Or when we are delayed in a queue and unintentionally hear interesting details in a stranger's mobile phone conversation. The sub-affordances of accessibility, explorability, multireachability, and slowability all affect how resources may be connected and how these connections may be traversed. These sub-affordances thus all cover what McCay-Peet and Toms (2015) call “enables connections", cf. Table 1, as "[s]omething or someone who encourages exploration, critical thinking, and the sharing of knowledge and ideas that make it possible to see relationships between information and ideas" (p.1471). 


\section{Mobility as coupled with traversability}

In the framework, cf. Table 2, mobility is a key personal serendipity factor coupled with the key affordance of traversability. It is suggested that the richer affordances for accessibility, multireachability, explorability, and slowability provided by an environment, the more our mobility may be stimulated. Discussing characteristics of chance, Austin (1978) emphasizes sensory-motor aspects: "The four kinds of chance each have a different kind of motor exploratory activity and a different kind of sensory receptivity" (p.70). His 'Chance II' "favors those in motion” (p.76), thus resonating with all mobility sub-factors and their coupled traversability sub-affordances, cf. Table 1 . In the framework, mobility is suggested to cover four personal sub-factors: searching, immersion, exploring, and stumbling. In the present affordance approach, these are seen as essentially coupled with the four sub-affordances of traversability outlined above and all deal with different motoric approaches when we interact with an environment.

Searching, the first personal sub-factor of mobility is in Table 2 coupled with the sub-affordance of accessibility. Serendipity may thus happen when we already are on the move in environments accessible for us, searching for something goal-directedly, convergently (Björneborn, 2008), and then in unplanned ways encounter something related to that foreground interest. In the often-cited serendipitous scientific discovery in 1928 by Alexander Fleming, he was thus already searching for antibacterial remedies when penicillium mold incidentally diffused into his lab and petri dishes (Roberts, 1989).

Immersion, the second personal sub-factor of mobility is seen as coupled with the sub-affordance of multi-reachability. Immersion connotes embodied, engaged behaviour that may cover both convergent, goal-directed and divergent, exploratory actions (terminology from Björneborn, 2008). As already cited, McCay-Peet and Toms (2011) see "immersion in an information-rich environment" perhaps as inevitably leading to serendipity.

Exploring, the third personal sub-factor of mobility is coupled with the sub-affordance of explorability. Exploratory, divergent behaviour may expand our information horizons and lead to serendipitous encounters. From an evolutionary approach, Bates (2007) discusses why we and other "motile" (capable of moving) animals explore the surrounding world: "In motile (as opposed to sessile) animals, exposure to new environments or new stimuli or new information all bring with them the possibility of discovering new food sources, new mates, new nesting or sleeping sites, or new ways to escape predation. Thus, the ability to move, combined with the ability to sense the environment, had a positive payoff for the animal with these capabilities" (ibid.).

Stumbling, the fourth personal sub-factor of mobility is coupled with the sub-affordance of slowability. 'Coming across', 'happening upon', 'stumbling upon' are synonymous phrasings for 
serendipitous encounters. Stumbling is also a way of slowing down our pace - in divergent or convergent ways - allowing us to make use of things that perhaps first seem like obstacles.

\subsection{Sensoriability}

Sensoriability deals with the quality or capacity of an object or environment of being sensoriable, i.e. perceivable by the senses. In other words, how rich affordances are there for sensing different resources in a given environment, e.g., in a city or in a library? Not only by sight, but also by hearing, smelling, tasting, and touching. The term is a neologism inspired by the American architect Buckminster Fuller talking about "sensoriable, apprehendable, physical factors" [5].

Sensoriability as a key affordance for serendipity covers three sub-affordances based on Björneborn (2008); exposure [6], contrasts, and pointers (cf. Table 2), dealing with how resources in a given environment can stand out for our senses in different ways.

\section{Exposure}

The sub-affordance of exposure deals with the capacity of a given physical or digital environment to mediate and display contents in ways that can trigger our senses. Windows in a physical shopping center or pictures in a web shop may trigger serendipitous impulse purchases. In similar ways, exposure of book cover displays in physical libraries (Björneborn, 2008), "eye-level visibility" in museums (Wineman and Peponis, 2010), digital visualizations like the 'Bohemian bookshelf' (Thudt et al., 2012), or social media feeds (Sun et al., 2013) may trigger serendipity. Not only visual triggers may be in action. As noted above, other senses may also be triggered in serendipitous encounters. Human history is full of unplanned findings of new food ingredients we like the taste of, sometimes through apparent cooking failures turning out to be quite delicious. The cereal of corn flakes were discovered in such a serendipitous way by the Kellogg brothers in 1898 (Roberts, 1989: 223). In Table 1, van Andel's (1994) "repetition of surprising observation" covers situations when we need more than one exposure to realize the potential interestingness. McCay-Peet and Toms (2015) define "trigger-rich" as an "environment that contains sensory cues that have the potential to spark serendipity" (p.1471). Further, "highlights triggers" is defined as "[s]omething or someone who highlights, points to, or otherwise alerts an individual to triggers" (ibid.). In the present framework, cf. Table 1, all three sub-affordances of sensoriability may be considered as both "trigger-rich" and “highlighting triggers". The same sub-affordances also cover Austin's (1978) 'Chance III' as “concerned with personal sensory receptivity" (p.74). 


\section{Contrasts}

The sub-affordance of contrasts deals with the capacity of a given environment to let something saliently stand out from something else in ways that can trigger our senses. Simple spot lamps may accomplish such sensory-teasing variation and differentiation in urban areas, shops, libraries, museums, etc. Contrasts between "quiet zones" where our senses are not bombarded, and more focused "display zones" may also trigger our senses, e.g., in cities or libraries (Björneborn, 2008). Serendipity may thus happen because "it is easier to discover a useful navigable 'loophole' in an information system when there is a contrasting background of lucid order" (Björneborn, 2004: 230; italics in original).

Where the sub-affordance of exposure may highlight contents "broader, over longer time", cf. Table 2, contrasts may highlight contents "sharper, more suddenly". The classical English landscape garden (e.g., Gabriel et al., 2014: 335) contains deliberately designed contrasts in terrain, vegetation, clearings, winding paths, etc., to create sensory experiences that may surprise and enjoy visitors. Similar contrasting features can be found in attractive libraries, urban areas, etc. (cf. Gehl, 2006). Also "interruption", "scarcity”, and “disturbance” (van Andel, 1994), “anomalies” (Merton, 1948), "exceptions" (Bawden, 1986), cf. Table 1, as well as other 'asymmetries' may be essential to make us notice contrasting occurrences with affordances for serendipity.

\section{Pointers}

The sub-affordance of pointers deals with the capacity of a given environment to highlight contents in "narrower, more specific" ways, cf. Table 2. Signage, maps, markers, cues, references, etc. (Björneborn, 2008) may thus trigger users' senses and interests allowing "both planned and unplanned findings" (ibid.), e.g., in a library or urban area. Simplicity and clarity creating overview of an environment may make it easier to notice potentially interesting contents. Curation, recommendations, reminders, and other channelings of contents in both physical and digital environments may also stimulate serendipity helping people discover things they perhaps had forgotten or did not know. In Table 1, "analogy" (van Andel, 1994), “analogies”, "patterns” and "tailoring user requirements" (Bawden, 1986) are related to the sub-affordance of pointers. Moreover, pointers can be both "trigger-rich" and "highlight triggers" (McCay-Peet and Toms, 2015), as well as they may "enable connections" and "enable capturing" as "[s]omething or someone who helps an individual record or copy a trigger for later use" (ibid.: p.1471). 


\section{Sensitivity as coupled with sensoriability}

In the framework, cf. Table 2, human sensitivity is seen as a key personal serendipity factor coupled with the key affordance of sensoriability. It is suggested, that the richer affordances for exposure, contrasts, and pointers provided by an environment, the more our sensitivity may be triggered.

Sensitivity, i.e. our sensory capabilities, is the other component of the sensory-motor abilities earlier mentioned by Austin (1978). In an urban context, Levý (2011: 45) emphasizes the importance of all our senses for serendipity: "Serendipity is fundamentally based on the presence of bodies available for a multi-sensoriality cognitive experience." In the present framework, the personal serendipity factor of sensitivity is suggested to cover three personal sub-factors: attention, surprise, and experience. These are seen as coupled with the three sub-affordances of sensoriability outlined above and all deal with different sensory approaches when we interact with an environment. As already stated, the personal sub-factors are only briefly addressed due to size limits of this paper.

Attention, the first personal sub-factor of sensitivity, is coupled with the sub-affordance of exposure. Being attentive is crucial for noticing serendipitous affordances. This resonates with related research, cf. Table 1, "act of noticing: observation/attention" (Rubin et al., 2011), "being observant" (Makri et al., 2014); all related to 'Chance III' "concerned with personal sensory receptivity" (Austin, 1978: 74).

Surprise, the second personal sub-factor of sensitivity is coupled with the sub-affordance of contrasts. In related research, cf. Table 1, similar terms are used: 'unanticipated' (Merton, 1948), 'surprising observation' (van Andel, 1994), and 'unexpected' (Makri and Blandford, 2012); all related to 'Chance III' (Austin, 1978) like above. Further below are discussed how different degrees of surprise may shape different degrees of serendipity.

Experience, the third personal sub-factor of sensitivity is coupled with the sub-affordance of pointers. McCay-Peet and Toms (2015) include "prepared mind" and "ability to make connections", both related to the individual's knowledge and experience, cf. Table 1. Also Rubin et al. (2011) include "prepared mind" ("prior concerns + experiences"), Makri et al. (2014) "previous experiences", Bogers and Björneborn (2013) "preoccupation", and Austin (1978: 76) states that 'Chance III' "favors the prepared mind". 'Preoccupation' is discussed below regarding different types of serendipity.

\section{Discussion}

\subsection{Affordance approach to serendipity}

As stated in the introduction, potential correspondences between environmental and personal factors are key to the theory of affordances founded by Gibson (1977). An important aspect in affordance 
theory is that affordances do not reside inside an environment alone nor inside people alone but reside in the relation between people, a given environment, and the actions that are possible for people in this environment (cf. Dourish, 2004: 118). Similarly, serendipity does not reside inside the environment alone nor inside people alone but reside in the relation - the correspondence - the encounter - between people and a given environment. Serendipity can thus be viewed as an affordance; as a relational phenomenon; as a usage potential (Björneborn, 2008) in a given environment that may be unfolded by persons with corresponding abilities, cf. the personal factors and sub-factors in Table 2. This means the outlined framework has a double-sided affordance approach to serendipity: serendipity as an affordance, and affordances for serendipity. Understanding that both environmental and personal factors covered by Table 2 influence affordances for serendipity is important for the design of such affordances in physical and digital environments. In order to establish such an understanding, essential couplings between the personal factors and sub-factors and the three key affordances and 10 sub-affordances for serendipity have been outlined in the conceptual framework in the previous sections.

The affordance approach to serendipity can be identified in the letter Sir Horace Walpole wrote to a good friend in 1754 coining the term 'serendipity' inspired by the fairy tale Three Princes of Serendip: "serendipity [...] making discoveries, by accidents and sagacity, of things which they [the princes] were not in quest of" (cited by Merton and Barber, 2004: 2). In Walpole's definition, serendipity thus covers both environmental ("accidents") and personal ("sagacity") factors, cf. Table 1. The environmental and personal aspects of affordances can also be seen in the double meaning of the word 'serendipity' today as both an occurrence/event (environmental) and a faculty/skill (personal).

\subsection{Different degrees and types of serendipity}

In the outlined framework, different degrees of diversifiability, traversability, and sensoriability in a physical or digital environment may correspond with different degrees of personal curiosity, mobility, and sensitivity. This may lead to different degrees and types of serendipity as discussed below.

In the introduction, serendipity was defined as happening "when we, in unplanned ways, encounter resources ... we find interesting”. Key terms here are unplanned, encounter, and interesting. Saying 'unexpected' or 'unplanned' when defining serendipity makes a difference, as unexpected events always are unplanned, but unplanned events are not always unexpected given the situation. For example, when we find a book not known to us in a library, it is unplanned. However, it is not unexpected nor surprising in a place filled with books. In the present framework, cf. Appendix A, unplannedness is seen as a spontaneous act akin to the personal serendipity sub-factor of playfulness. Using the term 'unexpected' might exclude micro-occurrences of serendipity like the unplanned 
library book example. Investigating micro-serendipity in everyday life shared on Twitter, Bogers and Björneborn (2013: 205) propose a serendipity continuum to cover "the entire spectrum of different degrees of surprise, from unplanned everyday incidents to unanticipated eureka moments in science", thus covering different degrees of serendipity. This echoes Makri and Blandford (2012) arguing against seeing serendipity as a discrete concept.

The term 'encounter' is also used by Erdelez (e.g., 1997) in her studies of "information encountering". If the definition above said "find resources" instead of "encounter resources" this would imply a more active search mode than necessarily always present in a serendipitous encounter. Neither does serendipity always depend on "finding something when searching for something else" as is sometimes stated. In fact, serendipity may happen when we are looking for something, and then, in unplanned ways, encounter something related to that foreground interest. Just like in the earlier mentioned discovery of penicillin by Alexander Fleming. An everyday example could be when we look for a piece of information but do not find it. Later on, entering another environment, e.g., a social media platform, for another reason, we may encounter the earlier sought-for piece of information without anticipating it.

There is also a difference saying 'valuable', 'useful', or 'interesting' when defining serendipity. The above-mentioned serendipity continuum thus ranges from interesting micro-serendipitous encounters in everyday life to highly valuable and useful findings in science. The tweets hashtagged \#serendipity by users in Bogers and Björneborn's (2013) study contained many examples of microserendipity not necessarily 'useful' in an instrumental sense, but perhaps 'just' emotionally interesting or entertaining, e.g., suddenly hearing the same music online we have just been humming to ourselves. As earlier noted, people may have innumerable interests during a lifetime; big and small, longer-lasting and temporary interests. Unplanned encounters related to any of all these interests may trigger serendipity. What a person considers as serendipitous depends on what the person in a given situation considers as unplanned and what the person in that situation considers as interesting. People thus have different serendipity thresholds (ibid.) for what they consider serendipitous. In other words, there may be different degrees of serendipity for different people in different kinds of situations.

Related to 'interestingness' are factors like preoccupation and prepared mind. Depending on the degree of preoccupation, one may differentiate between two main types of serendipity: foreground and background serendipity (ibid.). Background serendipity (or 'traditional' serendipity) is characterized by unplanned encounters of something related to a background, perhaps latent, interest; possibly changing a person's immediate focus and direction. For example, in the library encountering a displayed book on a topic we have not dealt with for a long time but now triggering a renewed interest. Foreground serendipity (or 'synchronicity' (cf. Bogers and Björneborn, 2013), 'pseudoserendipity' (Roberts, 1989)) is characterized by unplanned encounters of something related to a 
foreground interest and preoccupation; possibly confirming a person's immediate focus and direction. Foreground serendipity is not only experienced in everyday life, like the above music example, but also in science (cf. Makri and Blandford, 2012) like Fleming above discovering penicillium when already searching for antibiotics. Thus, "the existence of intentionality does not rule out serendipity" (McCay-Peet, 2013: 11).

Being an encounter we consider both unplanned and interesting, serendipity can be viewed as a 'control clash', being both within and beyond our influence and control (cf. McBirnie, 2008). Coincidence, chance, and unplannedness can be seen as 'perceived non-control' [7], i.e. beyond our influence, thus person-independent; the environmental component of affordances as an environmentactor correspondence. Whereas interest can be seen as 'perceived control', i.e. within our influence, thus person-dependent; the actoral component (cf. the personal factors in Table 2) of affordances as an environment-actor correspondence. In other words, serendipity can be seen as a 'clash' when perceived non-control meets perceived control.

Micro-serendipity (Bogers and Björneborn, 2013), i.e. everyday life encounters of potentially interesting things in unplanned ways, means serendipity is not a rare phenomenon, as otherwise sometimes stated (e.g., André et al., 2009). As noted by Bates (2010: 2381), "probably the largest amount of all information taken in by human beings is that received passively-simply through being aware - that is absorbed in the context of daily living." Serendipity may thus be so commonplace an experience that we do not always reflect on it. Our ways of getting information from the world are thus "often quite unselfconscious" (ibid.: 2386). In fact, serendipity may constitute a more essential part of our life than we perhaps register in a world filled with so much planning, control, and presumed rationality. In a similar vein, van Andel (1992: 29) notes how "the role of serendipity in science, technology and art is underestimated - because we rationalize a posteriori”. Accordingly, encountering potentially interesting things in unplanned ways may be seen as a deeply integrated part of our lives, and serendipity thus may play an essential - and commonplace - role in how we learn things in the world.

\subsection{Design implications incl. affordances for serendipity in physical vs digital environments}

Recent years have seen many suggestions - some more or less hyped - on how serendipity can be “accelerated”, “designed”, “engineered”, “enhanced”, "manufactured”, "maximized”, “orchestrated”, “planned”, "programmed”, etc., etc. [8].

However, serendipity per se cannot be "engineered". We cannot design environments always leading to serendipity - as serendipity is a highly subjective and situational phenomenon. But affordances for serendipity can be engineered. Affordances of diversifiability, traversability, and sensoriability may facilitate serendipity - but with no guarantee - as not all people may have time, 
energy, abilities, interests, etc., to make use of these affordances. So, seen from the user - the potential serendipitist (van Andel, 1994: 645) - it does not make sense to talk about "engineered serendipity", as serendipity must be encountered in unplanned ways (still as seen from the user) in order to be serendipitous. Serendipity may thus be intended by designers, but must always be unplanned by users.

When designing affordances that may facilitate serendipity it is important also to make design that at least does not inhibit serendipity. For example, automated book-sorting machines in libraries may hinder serendipity, if this means users no longer get access to book trolleys to explore what other users have returned.

In physical environments like urban areas, library buildings, museums, schools, work places, shopping centers, residential areas, roadsides, etc., our physical bodies allow full-sensory experiences (cf. Pallasmaa, 2005). Hence, rich sensoriability of physical environments may trigger personal sensitivity less possible in digital environments, where typically only sight and hearing are activated. In digital environments like web sites, social media, databases, digital libraries, digital museums, corporate intranets, etc., hyperlink structures allow quick movements between disparate resources and topics (cf. Björneborn, 2004). Rich traversability of digital environments may trigger personal mobility less possible in physical environments, where transportation of people and resources typically take longer time. It is thus suggested here that physical environments may have a primacy regarding affordances of sensoriability for facilitating serendipity, and digital environments a primacy regarding traversability. It is also suggested that physical and digital environments may afford similar degrees of diversifiability for facilitating serendipity. No research has been found that indicates different degrees of diversifiability in physical or digital environments. Intuitively we may grasp this, as, for instance, both urban areas and social media may be densely filled with a diversity of people, objects, information, etc. In other words, richer physical sensoriability and richer digital traversability may result in different affordances for serendipity in physical and digital environments, suggesting a differentiation between physical serendipity and digital serendipity. Designing environments with digital and physical components that can support and supplement each other may here be a fruitful direction for facilitating serendipity (cf. Björneborn, 2011).

As earlier indicated regarding the personal mobility sub-factors, serendipity may happen as a combination of divergent (exploratory) and convergent (goal-directed) information behaviour (Björneborn, 2008), e.g., when something divergently attracts our attention and we then convergently examine it. By definition, diversifiability deals with divergent affordances of environments, whereas traversability and sensoriability may have both divergent and convergent implications, as also indicated by the terminology in Table 2. For example, the traversability of library aisles may help users find preplanned items in convergent, goal-directed ways. However, the same aisles may help other users browse the shelves in divergent, exploratory ways. Analogously, the sensoriability of 
Braille signs in an urban area may convergently help blind persons find specific city locations, and the same signs may make other persons discover alternative and divergent directions. Hence, it may be a good idea to consider possible balances and complementarities between affordances for both convergent and divergent behaviour when designing physical and digital environments that may facilitate serendipity.

How could a serendipity-facilitating environment look like based on the framework principles? It could look like the library used many times in this paper to exemplify different elements of the framework. A library with a high degree of diversifiability - containing a rich variety of media, genres, topics, etc.; letting these resources meet across boundaries; allowing user-generated and perhaps incomplete resources to be included - facilitates serendipity. Adding high degrees of traversability and sensoriability in this library, using complementary physical and digital features making use of sub-affordances outlined in this article; including easy accessibility, reachability along multiple routes, curiosity-teasing explorability, as well as possibilities to slow down, sit down and reflect, combined with exposure of resources also using contrasts and pointers - further facilitates serendipity.

\section{Conclusion}

In all fields of life, we live at edges between known and unknown worlds, and serendipity can help us explore these edges, both in research, art, business, everyday life, etc.

In this paper, the outlined conceptual framework has aimed to provide terminological 'building blocks' for understanding connections between environmental and personal factors in serendipitous encounters. Understanding these connections is essential when designing affordances in physical and digital environments that can facilitate serendipity.

All the terminological 'building blocks' in the framework seem to resonate with the included related research (Table 1). The outlined framework literally covers the span between Walpole's terms from 1754, "accidents" and "sagacity" at opposite ends of Table 1. As shown in the table, the framework has most fine-grained matches with McCay-Peet and Toms (2015) and van Andel (1994) who cover both environmental and personal serendipity factors. Table 1 also shows where there are less matches between the included research approaches to serendipity. Interestingly, most included research seems to have less focus on motoric aspects (traversability and mobility) than the outlined framework. The framework may thus call for attention, of both researchers and designers, to details of affordances and personal factors - and couplings between them, cf. Table 2 - that may facilitate serendipity. In this context, future research will investigate how other relevant research than included in the paper may contribute to the 'building blocks' in a continued theoretical validation of the conceptual framework that also includes the keyword table in Appendix A. Accordingly, the outlined 
framework is open for future readjustments. However, as already stated, no other research has been found addressing affordances for serendipity and connections between environmental and personal factors in similarly detailed ways. The outlined framework and typology may thus function as a baseline for further serendipity studies.

In future research, the framework needs further empirical validation in physical and digital environments. Focus in the paper has been on presenting and discussing the three key affordances and ten sub-affordances for facilitating serendipity. Future studies will also delve further into the couplings with personal factors and sub-factors only briefly addressed in the paper.

In the outlined affordance approach to serendipity, serendipity is viewed as a relational phenomenon happening because environmental and personal factors correspond in complex ways. As discussed in the paper, different degrees of diversifiability, traversability, and sensoriability in a physical or digital environment may correspond with different degrees of personal curiosity, mobility, and sensitivity - and lead to different degrees of serendipity. Basic factors in the ways we interact with the world are thus at stake in serendipitous encounters: to what degree environments can be diversified, traversed, and sensed - and to what degree we are curious, mobile, and sensitive. In this context, the outlined affordance approach to serendipity points to the importance of our bodies, including our sensory-motor abilities, to discover and explore serendipitous affordances.

As argued in the paper, we cannot "engineer" nor "design" serendipity per se. We cannot design environments that always lead to serendipity - as serendipity is a highly subjective and situational phenomenon. Serendipity for one person is thus not necessarily serendipity for another person, and serendipity at one point in time is not necessarily serendipity at another time for the same person. However, even if we cannot "design serendipity", we can design for serendipity. That is, we can design affordances for serendipity - seen from the designers' point of view. From the users' point of view, serendipity must always be encountered in unplanned ways in order to be serendipitous.

The outlined framework does not imply that we should overfill environments with diversifiable, traversable, and sensoriable affordances as this may be counterproductive and create overload. When designing affordances for serendipity there should thus be found a balance between diversifiability, traversability, and sensoriability that can work well together in relation to both convergent (goaldirected) and divergent (exploratory) user behaviour in a given environment, whether it is an urban area, library, workplace, web site, etc. As noted throughout the paper, urban areas and libraries are good examples of design that already work well in many places - sometimes perhaps unintentionally - regarding diversifiability, traversability, and sensoriability. In this context, the paper has also suggested that richer physical sensoriability and richer digital traversability may support and supplement each other when both digital and physical components are included in the design of 
environments in order to facilitate serendipity. Libraries could - perhaps more than they sometimes do today - develop a role as intentional providers of both physical and digital serendipity.

Defining serendipity as what happens when we, in unplanned ways, encounter resources (information, things, people, etc.) that we find interesting, in the paper led to a discussion of different degrees of serendipity due to different degrees of unplannedness, encountering, and interestingness. Furthermore were discussed two main types of serendipity, foreground and background serendipity, depending on whether a foreground or background interest of a person is triggered.

Following the above definition, serendipity actually happens every time we, in unplanned ways, encounter resources that we find interesting in relation to our countless number of smaller and bigger, emerging or already established interests. As argued in the paper, serendipity may thus be viewed as a commonplace phenomenon in everyday life. So commonplace that we perhaps not always reflect upon it in a world with immense and complex multitudes of contents, interactions, encounters, and interests. Nevertheless, as we live in a world full of potentially interesting things, serendipity may help us discover, explore, and learn these things - all life long.

\section{Notes}

[1] Cf. selected haiku from research project in Appendix B, e,g, haiku no. 016 "looking for answers/ finding new questions as well --/ serendipity"; no. 196 "all incompleteness/ leaves the world open to us --/ serendipity"; no. 431 "serendipity/ spontaneously learning/ from unplanned findings".

[2] http://www.webster-dictionary.org/definition/Diversifiability (accessed May 10, 2017)

[3] Björneborn (2008) used the term 'imperfection'.

[4] Lori McCay-Peet on $\mathrm{PhD}$ project page in 2012, available at Internet Archive: https://web.archive.org/web/20120419005236/http://informatics.management.dal.ca/node/65 (accessed May 10, 2017) https://web.archive.org/web/20150920134426/www.lauralee.com/news/bucky2000.htm (accessed May 10, 2017)

[6] Björneborn (2008) used the term 'display'.

[7] Cf. Rubin et al. (2011): “Chance: [...] perceived lack of control”.

[8] E.g., http://www.nytimes.com/2013/04/07/opinion/sunday/engineering-serendipity.html?_r=0; http://www.lifescientist.com.au/content/biotechnology/article/orchestrating-serendipity-560729661 (accessed May 10, 2017) 


\section{References}

Abrahamson, E. and Freedman, D.H. (2007), A Perfect Mess : The Hidden Benefits of Disorder : How Crammed Closets, Cluttered Offices, and Off-The-Cuff Planning Make the World a Better Place, Phoenix, London.

Agarwal, N.K. (2015), “Towards a definition of serendipity in information behaviour”, Information Research, Vol. 20 No. 3, paper 675, available at: http://InformationR.net/ir/20-3/paper675.html (accessed May 10, 2017).

Åkerström, M. (2013), “Curiosity and serendipity in qualitative research”, Qualitative Sociology Review, Vol. 9 No. 2, pp. 10-18.

Anderson, T.D. (2013), "The 4Ps of innovation culture: Conceptions of creatively engaging with information", Information Research, Vol. 18 No. 3, paper C28, available at: http://InformationR.net/ir/18-3/colis/paperC28.html (accessed May 10, 2017)

André, P., schraefel, m.c., Teevan, J. and Dumais, S.T. (2009), "Discovery is never by chance: Designing for (un)serendipity", in Proceedings of the $7^{\text {th }}$ ACM conference on Creativity and Cognition, ACM, New York, NY, pp. 305-314.

Austin, J.H. (1978/2003), Chase, Chance, and Creativity : The Lucky Art of Novelty, The MIT Press, Cambridge, Mass.

Bandura, A. (1982), “The psychology of chance encounters and life paths”, American Psychologist, Vol. 37 No. 7, pp. 747-755.

Bardone, E. (2016), "Intervening via chance-seeking”, in Secchi, D. and Neumann, M. (Eds.), AgentBased Simulation of Organizational Behavior : New Frontiers of Social Science Research, Springer, New York, NY, pp. 203-220.

Bates, M.J. (2007), "What is browsing-really? A model drawing from behavioural science research", Information Research, Vol. 12 No. 4, paper 330, available at: http://InformationR.net/ir/12-4/paper330.html (accessed May 10, 2017).

Bates, M.J. (2010), “Information behavior”, in Encyclopedia of Library and Information Sciences, 3. ed., Taylor \& Francis, London, pp. 2381-2391.

Bawden, D. (1986), "Information systems and the stimulation of creativity", Journal of Information Science, Vol. 12 No. 5, pp. 203-216.

Benjamin, W., Chandrasegaran, S., Ramanujan, D., Elmqvist, N., Vishwanathan, SVN and Ramani, K. (2014), "Juxtapoze: Supporting serendipity and creative expression in clipart compositions", in Proceedings of the ACM Conference on Human Factors in Computing Systems (CHI 2014), ACM, New York, NY, pp. 341-350.

Björneborn, L. (2004), Small-world link structures across an academic Web space : A library and information science approach, Unpublished $\mathrm{PhD}$ dissertation, Royal School of Library and 
Information Science, Copenhagen, Denmark, available at: http://bit.ly/1Tvfw40 (accessed May 10, 2017).

Björneborn, L. (2008), Serendipity dimensions and users' information behaviour in the physical library interface, Information Research, Vol. 13 No. 4, paper 370, available at: http://InformationR.net/ir/13-4/paper370.html (accessed May 10, 2017).

Björneborn, L. (2011), Behavioural traces and indirect user-to-user mediation in the participatory library, in Proceedings of the International Conference Information Science and Social Media (ISSOME 2011), pp. 151-166.

Bogers, T. and Björneborn, L. (2013), "Micro-serendipity: Meaningful coincidences in everyday life shared on Twitter", in Proceedings of iConference 2013, pp. 196-208, available at: http://hdl.handle.net/2142/36052 (accessed May 10, 2017).

Buchem, I. (2011), "Serendipitous learning: Recognizing and fostering the potential of microblogging”, Formare Open Journal, No. 74, February/March 2011.

Case, D.O. and Given, L.M. (2016), Looking for Information: A Survey of Research on Information Seeking, Needs and Behavior, 4. ed., Emerald, Bingley, UK.

Chan, S. (2007), "Tagging and searching: Serendipity and museum collection databases", in Proceedings of Museums and the Web 2007, available at: http://www.museumsandtheweb.com/mw2007/papers/chan/chan.html (accessed May 10, 2017).

Darbellay, F., Moody, Z., Sedooka, A. and Steffen, G. (2014), “Interdisciplinary research boosted by serendipity”, Creativity Research Journal, Vol. 26 No. 1, pp. 1-10.

Dew, N. (2009), "Serendipity in entrepreneurship", Organization Studies, Vol. 30 No. 7, pp. 735753.

D’Ignazio, C. (2014), "Design strategies for serendipity and how they might fail", MIT Center for Civic Media, available at: https://civic.mit.edu/design-strategies-for-serendipity (accessed May 10, 2017).

Dörk, M., Carpendale, S. and Williamson, C. (2011), "The information flaneur: A fresh look at information seeking", in Proceedings of CHI 2011, pp. 1215-1224.

Dourish, P. (2004), Where the Action Is : The Foundations of Embodied Interaction, The MIT Press, Cambridge, Mass.

Doyle, L.B. (1963), “Is relevance an adequate criterion in retrieval system evaluation?”, in Proceedings of the American Documentation Institute $26^{\text {th }}$ Annual Meeting, American Documentation Institute, Washington D.C., pp. 199-200.

Erdelez, S. (1997), “Information encountering: A conceptual framework for accidental information discovery", in Proceedings of an International Conference on Information Seeking in Context (ISIC '96), Taylor Graham, London, pp. 412-421. 
Fine, G. and Deegan, J. (1996), “Three principles of Serendip: Insight, chance, and discovery in qualitative research", Qualitative Studies in Education, Vol. 9 No. 4, pp. 434-447.

Foster, A.E. and Ellis, D. (2014), "Serendipity and its study”, Journal of Documentation, Vol. 70 No. 6, pp. 1015-1038.

Frankel, J.A. (1979), "The diversifiability of exchange risk", Journal of International Economics, Vol. 9 No. 3, pp. 379-393.

Gabriel, Y., Muhr, S.L. and Linstead, S. (2014), "Luck of the draw? Serendipity, accident, chance and misfortune in organization and design", Culture and Organization, Vol. 20 No. 5, pp. 334341.

Gehl, J. (2006), Life between Buildings : Using Public Space, 6. ed., Danish Architectural Press, Copenhagen, Denmark.

Gibson, E.J., Riccio, G., Schmuckler, M.A., Stoffregen, T.A., Rosenberg, D. and Taormina, J. (1987), "Detection of the traversability of surfaces by crawling and walking infants", Journal of Experimental Psychology: Human Perception and Performance, Vol. 13 No. 4, pp. 533-544.

Gibson, J.J. (1977), "The theory of affordances", in Shaw, R. and Bransford, J. (Eds.), Perceiving, Acting, and Knowing : Toward an Ecological Psychology, Halsted Press, New York, NY, pp. 6782.

Gopnik, A. (2011), "Why preschool shouldn't be like school”, Slate, Nov. 16, 2011, available at: http://www.slate.com/articles/double_x/doublex/2011/03/why_preschool_shouldnt_be_like_scho ol.html (accessed May 10, 2017).

Hand, D.J. (2015), The Improbability Principle: Why Coincidences, Miracles, and Rare Events Happen Every Day, Scientific American / Farrar, Straus and Giroux, New York, NY.

Handelsman, J. (2015), “The value of basic research", The White House [blog], June 2, 2015, available at: https://obamawhitehouse.archives.gov/blog/2015/06/02/value-basic-research (accessed May 10, 2017)

Hart, J. (2004), “A new way of walking”, Utne Reader, July/August 2004, available at: http://www.utne.com/community/a-new-way-of-walking.aspx (accessed May 10, 2017).

Hartel, J. (2014), "An arts-informed study of information using the draw-and-write technique", Journal of the Association for Information Science and Technology, Vol. 65 No. 7, pp. 1349-1367.

Hidi, S. and Renninger, K.A. (2006), “The four-phase model of interest development”, Educational Psychologist, Vol. 41 No. 2, pp. 111-127.

Hornecker, E., Swindells, S. and Dunlop, M. (2011), “A mobile guide for serendipitous exploration of cities", in Proceedings of ACM MobileHCI 2011, ACM, New York, NY, pp. 557-562. 
Jeffrey, P. and McGrath, A. (2000), "Sharing serendipity in the workplace", in Proceedings of the Third International Conference on Collaborative Virtual Environments, ACM, New York, NY, pp. 173-179.

Johnson, S. (2010), Where Good Ideas Come From: The Natural History of Innovation, Allen Lane, London.

Knudsen, G.H. and Lemmergaard, J. (2014), "Strategic serendipity: How one organization planned for and took advantage of unexpected communicative opportunities", Culture and Organization, Vol. 20 No. 5, pp. 392-409.

Levý, J. (2011), "The city is back (in our minds)", in Schmid, H., Sahr, W.D. and Urry, J. (Eds.), Cities and Fascination : Beyond the Surplus of Meaning, Ashgate, Farnham, UK, pp. 33-48.

Magurran, A.E. (1988), Ecological Diversity and Its Measurement, Princeton University Press.

Makri, S. and Blandford, A. (2012), "Coming across information serendipitously: Part 2 - A classification framework", Journal of Documentation, Vol. 68 No. 5, pp. 706-724.

Makri, S., Blandford, A., Woods, M., Sharples, S. and Maxwell, D. (2014), ““"Making my own luck”: Serendipity strategies and how to support them in digital information environments", Journal of the Association for Information Science and Technology, Vol. 65 No. 11, pp. 2179-2194.

McBirnie, A. (2008), "Seeking serendipity: The paradox of control”, Aslib Proceedings, Vol. 60 No. 6, pp. 600-618.

McCarthy, J.C. and Wright, P.C. (2005), "The enchantments of technology", in Blythe, M.A, Overbeeke, K., Monk, A.F. and Wright, P.C. (Eds.), Funology : From Usability to Enjoyment, Kluwer, Dordrecht, The Netherlands, pp. 81-90.

McCay-Peet, L. (2013), Investigating Work-Related Serendipity, What Influences It, and How It May Be Facilitated in Digital Environments, unpublished $\mathrm{PhD}$ dissertation, Dalhousie University, Canada, available at: http://hdl.handle.net/10222/42727 (accessed May 10, 2017).

McCay-Peet, L. and Toms, E.G. (2011), "Measuring the dimensions of serendipity in digital environments", Information Research, Vol. 16 No. 3, paper 483, available at: http://InformationR.net/ir/16-3/paper483.html (accessed May 10, 2017).

McCay-Peet, L. and Toms, E.G. (2015), "Investigating serendipity: How it unfolds and what may influence it", Journal of the Association for Information Science and Technology, Vol. 66 No. 7, pp. 1463-1476.

Merton, R.K. (1948), "The bearing of empirical research upon the development of social theory", American Sociological Review, Vol. 13 No. 5, pp. 505-515.

Merton, R.K. and Barber, E.G. (2004), The Travels and Adventures of Serendipity: A Study in Historical Semantics and the Sociology of Science, Princeton University Press, Princeton, NJ.

Norman, D. (1999), “Affordance, conventions, and design”, Interactions, Vol. 6 No. 3, pp. 38-42. 
Olma, S. (2012), The Serendipity Machine : A Disruptive Business Model for Society 3.0, Seats2meet.com, The Netherlands.

Pallasmaa, J. (2005), The Eyes of the Skin : Architecture and the Senses, Wiley, New York, NY.

Pariser, E. (2011), The Filter Bubble : What the Internet Is Hiding From You, Viking, London.

Paydarfar, D. and Schwartz, W. (2001), “An algorithm for discovery”, Science, Vol. 292 No. 5514, p.13.

Poirier, L. and Robinson, L. (2014), "Informational balance: Slow principles in the theory and practice of information behaviour", Journal of Documentation, Vol. 70 No. 4, pp. 687-707.

Rahman, A. and Wilson, M.L. (2015), "Exploring opportunities to facilitate serendipity in search", in Proceedings of the $38^{\text {th }}$ International ACM SIGIR Conference on Research and Development in Information Retrieval, ACM, New York, NY, pp. 939-942.

Resmini, A. (2013), “Architectures of information”, Études de Communication, No. 41, available at: http://edc.revues.org/5380 (accessed May 10, 2017).

Roberts, R.M. (1989), Serendipity : Accidental Discoveries in Science, Wiley, New York, NY.

Ross, C.S. (1999), "Finding without seeking : The information encounter in the context of reading for pleasure", Information Processing and Management, Vol. 35 No. 6, pp. 783-799.

Rubin, V.L., Burkell, J. and Quan-Haase, A. (2011), "Facets of serendipity in everyday chance encounters: A grounded theory approach to blog analysis", Information Research, Vol. 16 No. 3 , paper 488, available at: http://InformationR.net/ir/16-3/paper488.html (accessed May 10, 2017)

Silvia, P. (2008), “Interest - The curious emotion”, Current Directions in Psychological Science, Vol. 17 No. 1 , pp. 57-60.

Sonnenwald, D.H., Wildemuth, B.M. and Harmon, G.T. (2001), "A research method to investigate information seeking using the concept of information horizons: An example from a study of lower socio-economic student's information seeking behaviour", The New Review of Information Behaviour Research, Vol. 2, pp. 65-86.

Stirling, A. (2007), “A general framework for analysing diversity in science, technology and society”, Journal of the Royal Society Interface, Vol. 4 No. 15, pp. 707-719.

Sun, T., Zhang, M. and Mei, Q. (2013), "Unexpected relevance: An empirical study of serendipity in retweets", in Proceedings of the $7^{\text {th }}$ International AAAI Conference on Weblogs and Social Media (ICWSM 2013), The AAAI Press, Palo Alto, CA.

Taramigkou, M., Bothos, E., Christidis, K., Apostolou, D. and Mentzas, G. (2013), "Escape the bubble: Guided exploration of music preferences for serendipity and novelty", in Proceedings of the $7^{\text {th }}$ ACM conference on Recommender systems (RecSys'13), ACM, New York, NY, pp. 335338. 
Thudt, A., Hinrichs, U. and Carpendale, S. (2012), "The Bohemian Bookshelf: Supporting serendipitous book discoveries through information visualization", in Proceedings of the SIGCHI Conference on Human Factors in Computing Systems (CHI'12), ACM, New York, NY, pp. 14611470.

van Andel, P. (1992), "Serendipity: "Expect also the unexpected"”, Creativity and Innovation Management, Vol. 1 No. 1, pp. 20-32.

van Andel, P. (1994), “Anatomy of the unsought finding. Serendipity: Origin, history, domains, traditions, appearances, patterns and programmability", The British Journal for the Philosophy of Science, Vol. 45 No. 2, pp. 631-648.

Walpole, H. (1754/1960), "Letter to Horace Mann, January 28", in Lewis, W.S. (Ed.), The Correspondence of Horace Walpole, The Yale Edition, Vol. 20, Yale University Press, New Haven, CT, pp. 407-409.

Walz, S.P. (2010), Toward a Ludic Architecture : The Space of Play and Games, ETC Press, Pittsburgh, PA.

Wineman, J.D. and Peponis, J. (2010), “Constructing spatial meaning : Spatial affordances in museum design”, Environment and Behavior, Vol. 42 No. 1, pp. 86-109.

Yadamsuren, B. and Erdelez, S. (2010), "Incidental exposure to online news", in Proceedings of the American Society for Information Science and Technology, Vol. 47 No. 1, pp. 1-8.

Ziegler, C.-N., McNee, S.M., Konstan, J.A.; and Lausen, G. (2005), "Improving recommendation lists through topic diversification", in Proceedings of the 14th international conference on World Wide Web, $W W W$ '05, ACM, New York, NY, pp. 22-32.

Zuckerman, E. (2011), "Desperately seeking serendipity", keynote at CHI 2011, available at: http://www.ethanzuckerman.com/blog/2011/05/12/chi-keynote-desperately-seeking-serendipity/ (accessed May 10, 2017). 
Appendix A. Framework keywords for affordances and personal factors for serendipity. Based on literature reviews and research project haiku (Appendix B).

\begin{tabular}{|c|c|c|c|}
\hline 10 SUB-AFFORDANCES FOR SERENDIPITY & $\begin{array}{l}3 \text { KEY AFFORDANCES } \\
\text { FOR SERENDIPITY }\end{array}$ & $\begin{array}{r}3 \text { key personal factors } \\
\text { for serendipity }\end{array}$ & 10 personal sub-factors for serendipity \\
\hline $\begin{array}{l}\text { DIVERSITY [multiple potentials] } \\
\text { heterogeneity/ multiplicity/ multiverse/ complexity/ divergence/ diversion/ } \\
\text { disparity/ non-redundancy/ novelty/ unparalleled/ innumerability/ abundance/ } \\
\text { potentiality/ possibility space/ opportunity structure/ open-minded space/ open } \\
\text { world/ contingency/ coincidence/ accident/ luck/ chance/ tychism/... }\end{array}$ & \multirow[t]{3}{*}{ DIVERSIFIABILITY } & \multirow[t]{3}{*}{ curiosity } & $\begin{array}{l}\text { interest [regarding diversity etc.] } \\
\text { engagement/ desire/ neophilia/ openness/ participation/ open- } \\
\text { minded/ beginner's mind/ carpe diem/grasp/ choice/ pull/ seize/ } \\
\text { question/ learn/ make use of/ useful/strategic/ insight/ value/ } \\
\text { relevance/ purpose/ ... }\end{array}$ \\
\hline $\begin{array}{l}\text { CROSS-CONTACTS [colliding potentials] } \\
\text { edge/ contact surface/ threshold/ transition/ transcendence/ boundary crossing/ } \\
\text { cross-pollination/ diffusion/ exchange/ collision/ encounter/ intersection/ in- } \\
\text { between/ interstitial/ periphery/ margin/ otherness/ heterotopia/ bricolage/ } \\
\text { alternative narrative/ topic drift/ juxtaposition/ bisociation/ inversion/ out of box/ } \\
\text { spill-over/ side-effect/ combination/ combinatorics/ permutation/ reshuffling/ } \\
\text { reconfigurability/ remix/ change/ exaptation/ repurposing/... }\end{array}$ & & & $\begin{array}{l}\text { playfulness [regarding cross-contacts etc.] } \\
\text { homo ludens/ play/ ludic/ creativity/ imagination/ fantasy/ } \\
\text { humour/ joke/ improvisation/ spontaneity/ varying routines/ } \\
\text { unplannedness/ unintentional/ procrastination/ idle time/ flow/ } \\
\text { joy/ delight/ freedom/ non-control/ lateral thinking/ } \\
\text { heteroscopia/... }\end{array}$ \\
\hline $\begin{array}{l}\text { INCOMPLETENESS [ unfinalizable potentials] } \\
\text { imperfection/ 'wabi-sabi'/ crack/ fracture/gap/ discontinuity/ structural hole/ } \\
\text { unknown unknowns/yet-to-be-knowns/ unpredictability/ unforeseeability/ } \\
\text { randomness/ indeterminacy/ sloppiness/ messiness/ irregularity/ slippage/ slack/ } \\
\text { error/ ambiguity/ unspecificity/ imprecision/ asystematicity/ uncontrollability/ } \\
\text { chaos/antifragility/ infinite games/ unfinalizability/ impermanence/ inconsistency/ } \\
\text { instability/ evasiveness/ transientness/ left-behinds/ ... }\end{array}$ & & & $\begin{array}{l}\text { inclusiveness [regarding incompleteness etc.] } \\
\text { allowing imperfection, mistakes \& uncertainty/ irrationality/ } \\
\text { antifragility/ 'failing better'/ experiment/ giving a chance/ } \\
\text { relaxing boundaries/ mental space/ elasticity/ reaching out/ } \\
\text { flexibility/ acceptance/ trust/ generosity/ forgetting/... }\end{array}$ \\
\hline $\begin{array}{l}\text { ACCESSIBILITY [access to specific spot, convergently] } \\
\text { direct access/ access point/ touch point/ convergence/ entry/ door/ gateway/ } \\
\text { bridge/ connection/ findability/ searchability/ proximity/ proxemics/topology/ } \\
\text { space syntax/ structure/ texture/ fabric/ adjacent possible/ niche enablement/ } \\
\text { readiness-at-hand/ physicality/ close encounter/ ... }\end{array}$ & \multirow[t]{4}{*}{ TRAVERSABILITY } & \multirow[t]{4}{*}{ mobility } & $\begin{array}{l}\text { searching [convergent] } \\
\text { convergence/ wayfinding/ voyage/ following/ seeking/ foraging/ } \\
\text { hunting/ bringing back/ ... }\end{array}$ \\
\hline \begin{tabular}{|l|} 
MULTI-REACHABILITY [reaching anywhere, immersively] \\
hyperconnectivity/ hypertext/ connective space/ scalability/ liquid network/ \\
fluidity/ non-linearity/ intertwingularity/ entangledness/ rhizome/ interconnection/ \\
shortcut/ transversal/ tangent/ weak ties/ loophole/ small-world topology/ \\
crumpled-up-ness/ folds/ layers within layers/ interactionability/...
\end{tabular} & & & $\begin{array}{l}\text { immersion [both convergent \& divergent] } \\
\text { embodiment/ thrownness/ physical mobility/traverse/ interact/ } \\
\text { dance/ ... }\end{array}$ \\
\hline $\begin{array}{l}\text { EXPLORABILITY [inviting somewhere else, divergent/y] } \\
\text { exploratory capability/ walkability/ side road/ path/trail/stepping stone/ desire } \\
\text { line/ psycho-geography/ dérive/ stigmergy/loose space/... }\end{array}$ & & & $\begin{array}{l}\text { exploring [divergent] } \\
\text { divergence/ browsing/ flaneur/ meandering/ lurking/ passing by/ } \\
\text { straying away/ surfing/ wandering/ wanderlust/ ... }\end{array}$ \\
\hline $\begin{array}{l}\text { SLOWABILITY [affording slower pace, frictionally] } \\
\text { stopability/ friction/ 'stumblability'/ constraints/ inconvenience/ obstacles/ } \\
\text { unflattening/ detour/ density/ gravity/ persistence/ complementarity/ balance / } \\
\text { pause/ ... }\end{array}$ & & & $\begin{array}{l}\text { stumbling [both divergent \& convergent] } \\
\text { happen upon/ encounter/ come across/ dip into/ fall/ slip/ } \\
\text { detour/stop/ pause/ dwell/ slowness/... }\end{array}$ \\
\hline
\end{tabular}


EXPOSURE [highlighting broader, over longer time]

foreground/ display/ enable/ facilitate/ leave open/ window/ mediation/ narrative/ push/feed/stream/ visualization/ illumination/ aesthetics/ appeal/ attract/ invite/ augmentation/ expansion/ replicability/ repetition/ ...

\section{CONTRASTS [highlighting sharper, more suddenly]}

differentiation/ difference/ variation/ anomaly/ unusual/ asymmetry/ salience/

stand out/ distraction/ disturbance/ interruption/ disruption/ break/ peripety/

reverse/ shift/ twist/ paradox/ 'koan'/ perspective/ peekaboo/ suddenness/ leap out/ background/ non-obvious/ scarcity/ ...

POINTERS [highlighting narrower, more specifically]

map/ overview/ signage/ indexicality/ marker/ reference/ direction/ relation/ correspondence/ resonance/ reminder/ clue/ cue/ information scent/ prompter/ scaffolding/ simplicity/ clarity/ analogy/ similarity/ curation/ channel/ focus/guide/ recommendation/ point of view/...

\section{SENSORIABILITY}

(

sensitivity attention [broader sensing]

alertness/ awareness/ arousal/ enlightenment/

multi-sensory/see/ look/ hear/taste/ smell/ touch/ notice/

sense/ perceive/ being observant/ receive/ ...

\section{surprise [unprepared sensing]}

unpreparedness/ unexpectedness/ unanticipation/ discovery/

eureka/ wonder/ amazement/ empathy/ emotion/ uncertainty/

unfamiliarity/ confusion/ overload/getting lost/ ...

experience [prepared sensing]

preparedness/preoccupation/ predisposed/ ripeness/

incubation/ skills/ literacies/ knowledge/ sagacity/ intuition/ zen/

mindfulness/ sensemaking/ pattern recognition/opportunity recognition/ ... 
Appendix B. Selected from +450 haiku micro-poetry $(5+7+5$ syllables) made by the author on twitter.com/connecto; used as a reflection tool in the research process to extract essences of serendipity and keywords (cf. Appendix A) for the conceptual framework. A haiku may be placed under more than one subheading. Haiku terms related to a specific subheading are marked in bold below. See a complete list of the haiku micro-poetry at http://hum.ku.dk/lb/jdoc2017tables.pdf

\section{SERENDIPITY AFFORDANCES \\ DIVERSIFIABILITY}

\subsection{DIVERSITY [multiple potentials]}

$008 /$ serendipity/ traversing diverse terrains/ triggering senses

042/ serendipity/ cross-breeding disparity/ with proximity

$124 /$ serendipity/ chances inviting choices/inviting changes

$144 /$ serendipity/ coincides outside our plans/ wherever we go

$257 /$ serendipity/always new things to be found/ not planned to be found

$277 /$ contingent absence/ of impossibility --/ serendipity

291/ innumerable/ possible combinations --/ serendipity

296/ serendipity/ forever pushing our ways/ into novelty

320 / serendipity/neither inevitable/ nor impossible

$398 /$ serendipity/ multiverse diversity/ traversed by surprise

436/ serendipity/ opportunity-driven/ learning diverse life

439 / happening because/ life is full of potentials --/ serendipity

1.2. CROSS-CONTACTS [colliding potentials]

015/ serendipity/ lives at edges of networks/ connecting people

077/ serendipity/ emerging in in-betweens/ crossing transversals

095/ moments in movements/ transitions across thresholds --/ serendipity

$101 /$ serendipity/ reconfiguring edges/ redirecting walks

165 / the strength of weak ties/ seizing serendipity/ on cross-world bridges

$170 /$ serendipity/ seeds taking root in your world/ cross-pollinating

226/ serendipity/ relaying new relations/ between world and man

$237 /$ serendipity/ juxtaposing convergence/ joining divergence

$256 /$ serendipity/ playing with permutations/reshuffling edges

260/ serendipity/alternative narrative/ probing out of box

330 / serendipity/ perspectives of otherness/ opening new worlds

$350 /$ serendipity/ finding into otherness/ otherwise not found

$359 /$ serendipity/ as casual collisions/ across connections

366/ living at edges/ between known \& unknown worlds --/ serendipity

\subsection{INCOMPLETENESS [unfinalizable potentials]}

010 / serendipity/is foreseeable when the world/is unforeseeable

019 / serendipity/ in unforeseeable life/go see for yourself

033/ passing by roadsides / lifting left-behinds to life --/ serendipity

090/ maybe you do know/ serendipity can make/ unknown unknowns known

196/ all incompleteness/ leaves the world open to us --/ serendipity

203/ serendipity/ connecting unconnected/ odd yet fit pieces coupled personal serendipity factors

\section{curiosity}

2.1. interest [regarding diversity etc.]

$001 /$ serendipity/ unexpected relevance/ for experience

006/ serendipity/ finding unplanned ways to find/ interesting things

013/ learning all life long/ moving openly sensing/ serendipity

016/ looking for answers/ finding new questions as well --/ serendipity

047 / serendipity/ is when you both see and seize/ opportunity

$124 /$ serendipity/ chances inviting choices/ inviting changes

$191 /$ not found on purpose/ yet found to be purposeful --/ serendipity

$199 /$ serendipity/ realizations of chance/ encountering choice

$274 /$ a beginner's mind/ the world emerges anew --/ serendipity

275 / serendipity/ unintentional knowledge/ grasped by open minds

$402 /$ serendipity/ sense of possibility/ seizing the moment

406/ serendipity/ calling curiosity/ for new encounters

\section{2. playfulness [regarding cross-contacts etc.]}

076/ incident prompting/ improvised shift in intent --/ serendipity

096/ creativity/ playfully cultivating/ serendipity

140/ procrastinating/ serendipity driving/ideas forward

$189 /$ serendipity/ where imagination goes/ for alterations

240/ playing with loopholes/ ludic serendipity/ favors those in flow

$254 /$ let go - no control/ just find out where it takes you --/ serendipity

$271 /$ serendipity/ repurposing relevance/spontaneously

$309 /$ serendipity/at play with homo ludens/ playing unplanned ways

$326 /$ serendipity/ on edges of non-control/grasped by our control

$367 /$ serendipity/ life improvising with life/ thriving in free play

$375 /$ serendipity/ making life up as we go/ unfolding unplans

$399 /$ freedom grasping life/ unfolding what is unplanned/serendipity

413 / serendipity/ plays with possibilities/ exploring sideways

431/ serendipity/ spontaneously learning/ from unplanned findings

\section{3. inclusiveness [regarding incompleteness etc.]}

043/ serendipity/ happened to give chance a chance/ when I looked that way

078/ serendipity/ just wandering with no plans/ trusting digressions

098/ open minds giving/ serendipity a chance/ to finding its way

$279 /$ serendipity/ through flexible attention/ reframing action

298/ serendipity/ found no failed experiments/ just unplanned outcomes

$306 /$ serendipity/ following uncertainties/ failing better still 
245 / it is through the cracks/ serendipity gets in/ creating new light

247/ serendipity/ unfinalizable worlds/ unfolding unknowns

269/ only through unknowns/ is life constantly renewed --/ serendipity

278 / what is one man's trash/ may be another's treasure --/ serendipity

419/ serendipity/ discontinuous patterns/disclosing new paths

440/ yet-to-be-known worlds/ full of serendipity/luring towards us

443/ serendipity/ embracing the imperfect/ fitting across cracks

\section{TRAVERSABILITY}

1.4. ACCESSIBILITY [access to specific spots; convergently]

014/ serendipity/ within reach - beyond control/ matching mind with world

017/ serendipity/ in "adjacent possibles"/ just there next to you

042/ serendipity/cross-breeding disparity/ with proximity

057/ complementary/ divergence and convergence --/ serendipity

$317 /$ serendipity/ ever new doors behind doors/ expanding your house

389/ actualizing/ an adjacent possible --/ serendipity

1.5. MULTI-REACHABILITY [reaching anywhere; immersively]

065/ intertwingledly/ anything may untangle/ serendipity

086/ serendipity/ creative non-linear/ paths of engagement

$146 /$ on small-world shortcuts/ serendipity gateways/ boundary crossings

169/ rhizome roots reached out/ connecting diversities/ serendipities

171 / crumpled-up spaces/ serendipity unfolds/ across folds of folds

185 / unprecedented/ hyperconnectivity/ serendipity

$192 /$ serendipity/ as everything hangs/ on something else

1.6. EXPLORABILITY [inviting somewhere else; divergently]

111 / serendipity/as psychogeography/ probing displaced paths

132 / serendipity/ in desire lines beyond grids/making our own paths

147 / serendipity/ followed unplanned desire paths/ footsteps flowed astray

$167 /$ stumbling upon stones/ turned by serendipity/ into stepping stones

$216 /$ no path is needed/ whole forest invites walking --/ serendipity

254/ let go - no control/ just find out where it takes you --/ serendipity

1.7. SLOWABILITY [affording slower pace, frictionally]

068/ a good day today/ finding obstacle as path --/ serendipity

$167 /$ stumbling upon stones/turned by serendipity/ into stepping stones

272 / slowability/ allowing your flow catch up/serendipity

282 / serendipity/ seen as positive friction/ of colliding worlds

$355 /$ slowability/ frictions invite close sensing/ serendipity

385 / serendipity/ for unflattening flatland/ space made stumblable

\section{SENSORIABILITY}

1.8. EXPOSURE [highlighting broader, over longer time]

088/ serendipity/ design facilitating/ diverse encounters

$124 /$ serendipity/ chances inviting choices/ inviting changes
$310 /$ serendipity/ taking time to move and sense/ allowing slowness 409/ serendipity/ in heteroscopia/ seeing otherness

416 / serendipity/ when able to see bridges/ where others see holes 428 / no discovery/ without serendipity/giving chance a chance

434/ dipping in through doors/you happened to leave open --/ serendipity

443 / serendipity/ embracing the imperfect/ fitting across cracks

\section{mobility}

2.4. searching [convergent]

058/ strayed divergent dips/ into serendipity/ sparked convergent steps

069/ serendipity/getting lost in wayfinding/gave new walks a chance

148 / letting the dog out/ to chase crows under the stars/ he brings back the sun

$159 /$ serendipity/ is about going places/ where things can find you

213 / losing my bearings/ on a voyage to elsewhere/ I reached Serendip

239/ serendipity/ followed new twists in terrain/ flowing streams astray

2.5. immersion [both convergent \& divergent]

003 / serendipity/ meets mobile minds and bodies/ in wander-wonder

052/ necessarily/ you must move and sense to find/ serendipity

$211 /$ serendipity/ immersion in diversion/ engaged encounters

$230 /$ serendipity/ chance favors those in motion/ crossing boundaries

236/ serendipity/ interactions intersect/ ideas connect

$357 /$ serendipity/ moving into the unknown/ expanding your life

$441 /$ serendipity/ as no end remains the same/ when you start moving

\section{6. exploring [divergent]}

008/ serendipity/ traversing diverse terrains/ triggering senses

048/ co-working people/ value sharing ideas/ co-exploring chance

058/ strayed divergent dips/into serendipity/ sparked convergent steps

$250 /$ planless wandering/ serendipity in wake/ playful wondering

268/ exploring worlds filled/ with potentiality --/ serendipity

432/ serendipity/ walking open worlds/ meeting open minds

\section{7. stumbling [both divergent \& convergent]}

051/ whenever you fall/ pick something up - for instance/ serendipity

079/ serendipity/ design enabling wide range/ moves, stops, turns and flows

187 / stumbling makes us see/ beyond our own boundaries --/ serendipity

231/ serendipity/ unwinding from structured lives/ delightfully lost

$307 /$ coming on something/ by coming across something --/ serendipity $310 /$ serendipity/ taking time to move and sense/ allowing slowness

\section{sensitivity}

2.8. attention [broader sensing]

135 / seeing with new eyes/ what might else have been unseen --/ serendipity

$174 /$ serendipity/ what matters is what you see/ not what you look at 
148 / letting the dog out/ to chase crows under the stars/ he brings back the sun $160 /$ making use of things/ life happens to bring my way --/ serendipity

$196 /$ all incompleteness/ leaves the world open to us --/ serendipity

268/ exploring worlds filled/ with potentiality --/ serendipity

$301 /$ serendipity/as grasping affordances/ unplanned but perceived

1.9. CONTRASTS [highlighting sharper, more suddenly]

060/ serendipity/ between distract and focus/ in fluid balance

066/ serendipity/ as distraction can attract/ interest and joy

131 / serendipity/ stands out contrasting figure/ on your own background

243 / you can always find/ what you are not looking for --/ serendipity

251 / serendipity/ breaking equilibrium/ changing your focus

$358 /$ serendipity/ encountering otherness/ opened perspectives

393 / serendipity/ a difference/ making/ a difference of/ a difference // \#5lines

408 / serendipity/useful unusualness/usually works

1.10. POINTERS [highlighting narrower, more specifically]

060/ serendipity/ between distract and focus/ in fluid balance

076/ incident prompting/ improvised shift in intent --/ serendipity

084/ channeling chances/ challenging oft-trodden trails --/ serendipity

$136 /$ we crossed paths and changed/ one another's directions --/ serendipity

173 / serendipity/ pointing to new entry points/ wherever you are

$321 /$ encountered answers/ still when asking no questions --/ serendipity
$175 /$ doors of perception/ between things known and unknown --/ serendipity

$197 /$ serendipity/ looking beyond what you see/ may open your eyes

$279 /$ serendipity/ through flexible attention/ reframing action

$299 /$ serendipity/ meaningful coincidence/ as perceived by you

$384 /$ serendipity/ receiving more from the world/ than we are seeking

\section{9. surprise [unprepared sensing]}

$001 /$ serendipity/ unexpected relevance/ for experience

035/ explored wandering/ Serendip revisited/induced wondering

069/ serendipity/getting lost in wayfinding/gave new walks a chance

195/ one wow of surprise/ enough to experience/ serendipity

213 / losing my bearings/ on a voyage to elsewhere/I reached Serendip

$217 /$ not closed by belief/ my mind opened with wonder/ serendipity

$381 /$ serendipity/ poetry of universe/ surprising itself

425/ you just never know/ all what you may encounter --/ serendipity

\subsection{0. experience [prepared sensing]}

080 / serendipity/ collaborating with chance/ favors prepared minds

$102 /$ mindful the sweeper/ stumbles upon temple dust --/ serendipity

$118 /$ serendipity/ when chances and skills collide/ and collaborate

201/ serendipity/ you know it when you see it/ but not until then

$297 /$ serendipity/ inviting intuition/zen experience

405 / serendipity/ happens by coincidence/ you make meaningful 